Paper

\title{
Driven by complementary operation of SiC-MOSFET and SiC-JFET within isolated flyback converter circuit
}

\author{
Nobuo Satoh ${ }^{1 a)}$, Takaaki Hayashi ${ }^{1}$, Tatsuki Ohsato ${ }^{1,2}$, \\ Hiroshi Arai ${ }^{1}$, and Yasuyuki Nishida ${ }^{1}$ \\ ${ }^{1}$ Department of Electrical, Electronics and Computer Engineering, \\ Chiba Institute of Technology \\ 2-17-1 Tsudanuma, Narashino Chiba 275-0016, Japan \\ ${ }^{2}$ Department of Information and Image Sciences, Chiba University \\ 1-33 Yayoi-cho, Inage-ku, Chiba 263-8522, Japan \\ a) satoh.nobuo@it-chiba.ac.jp
}

Received November 20, 2017; Revised March 11, 2018; Published July 1, 2018

\begin{abstract}
Flyback converters are used in DC-DC conversion with electric isolation between the input and the output. In flyback converter circuits, a silicon carbide ( $\mathrm{SiC}$ ) metal-oxidesemiconductor field-effect transistor (MOSFET) and a silicon carbide junction gate field-effect transistor (JFET) are adopted as the switching and rectifying devices, respectively. SiC devices were controlled due to one signal, and a switching frequency of $1 \mathrm{MHz}$ was achieved. The voltage and current on the input and output sides in the flyback converter were observed as part of the circuit operation analysis. The power conversion efficiency was evaluated through waveform observation.
\end{abstract}

Key Words: flyback converter, megahertz-frequency switching, SiC power devices

\section{Introduction}

Multistep output DC circuits can be used as general-purpose low-power switching supplies [1]. In DC power supplies, a high-speed switching operation can decrease the amount of energy created in each cycle, which promotes the downsizing of the passive circuit elements such as inductors and capacitors [2]. Further, parasitic impedances in a circuit limit the operating frequency during highspeed switching. Switching losses occur because of a surge in voltage, the tail current, and ringing phenomena, which originate in both the circuit and the parasitic components of the active device [35]. The circuit and the device can be damaged by the losses generated due to Joule heating. One of the goals of our study is to suppress power-conversion losses. Since it is difficult to examine parasitic impedance in advance, circuit analysis is performed based on the experimental results in a manufactured circuit.

In this study, we use a flyback converter with a snubber circuit [6] operating at switching frequencies 
of $100 \mathrm{kHz}$ and $1 \mathrm{MHz}$, respectively. The circuit configuration of the flyback converter $[7,8]$ ensures that electric insulation is employed for most low-power switching supplies by using a high-frequency transformer, such as a choke coil, and a gate drive that insulates the control circuit and the principal power conversion circuit. In the circuit, two types of active devices are examined: trench-type metal-oxide-semiconductor field-effect transistor made of silicon carbide ( $\mathrm{SiC}$ ) as a switching power device (SiC-MOSFET) [9], and a junction-type field-effect transistor made of SiC (SiC-JFET) [10] as a rectifying power device. We investigate the transient behaviors of the converter for switching operations by utilizing each of the $\mathrm{SiC}$ power devices. Based on the expected experimental results, the design of the converter at high-power output and high-speed switching will then be examined.

\section{Experimental setup}

\subsection{Flyback converter circuit}

The flyback converter under investigation is shown in Fig. 1. The specified output voltage is $15 \mathrm{~V}$ at operating frequencies of $100 \mathrm{kHz}$ and $1 \mathrm{MHz}$. This circuit consists of two features. Firstly, this circuit was significantly advantageous for miniaturizing the power supply circuit with high-speed switching by using the $\mathrm{SiC}$ power devices. Secondly, this flyback converter is that it employs complementary devices, such as normally-off MOSFET and normally-on JFET. These devices are used mutually to achieve the switching operation of the transformer responsible for energy storage, and the rectification operation responsible for energy release. The active device responsible for switching and rectifying functions are described in the 2.2 section.

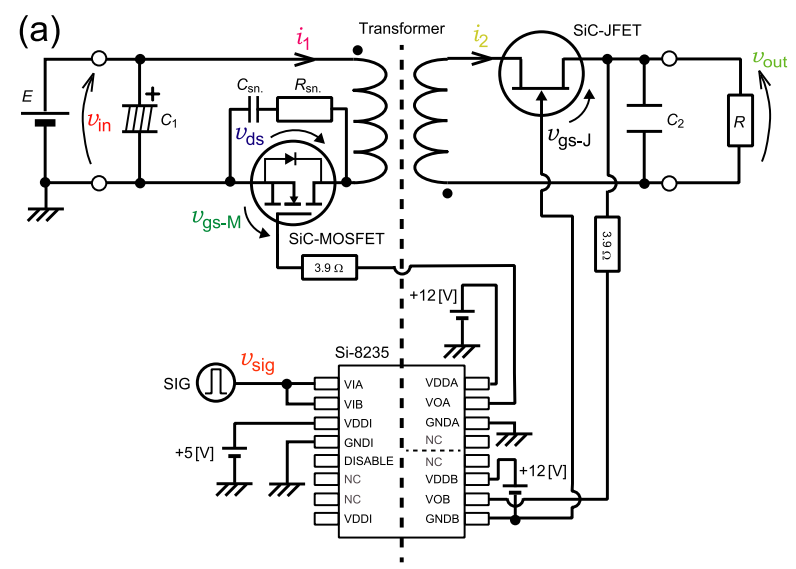

(b)

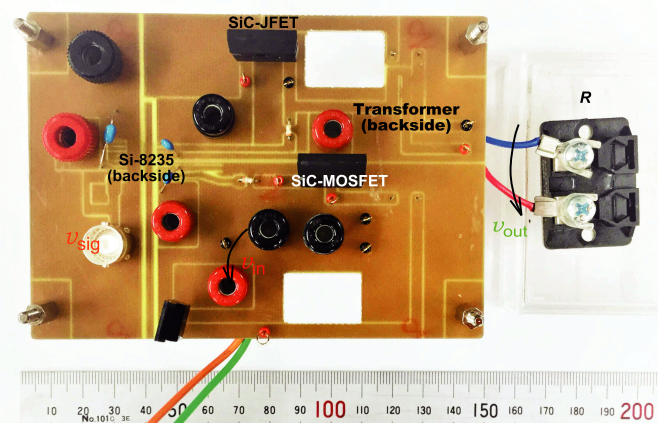

Fig. 1. (a) Schematic circuit diagram of flyback converter using isolated dualgate driver and transformer. (b) Photograph of the flyback converter.

The electric power supply $(E)$ is connected to the primary side of the transformer, which corresponds to the power input side. Noise generation is suppressed by connecting a constant voltage source (GP0110-3; Takasago ltd.) as the series regulation type. To manage the attainment voltage, an aluminum electrolytic capacitor $\left(C_{1}\right)$ with a charge capacity of $1500 \mu \mathrm{F}$ (withstand voltage: $250 \mathrm{~V}$; Nippon Chemi-Con Corp.) was connected to avoid voltage instability at the primary side. The resistance and capacitor $(R C)$ snubber circuit is connected with the power-MOSFET in parallel, and it was inserted to suppress the surge voltage. The circuit parameters of the $R C$ snubber circuit were $R_{\mathrm{sn}}=220 \Omega, C_{\mathrm{sn}}=2.2 \mathrm{nF}$, as shown in Fig. 1.

The secondary side of the transformer is connected to a load at the power output side. For highspeed switching operations, a laminated ceramic capacitor is selected as the smoothing capacitor $\left(C_{2}\right)$ on the output side. An electrolytic capacitor is preferred as it is more robust against damage caused by heat, smaller spatial volume, high permissible ripple electric current, and the small equivalent series resistance $(\mathrm{ESR})$. Based on the switching frequency $\left(f_{\mathrm{sw}}\right)$ and the accepted ripple rate, five $10 \mu \mathrm{F}$ (UMK316BBJ106KL-T, withstand voltage: $50 \mathrm{~V}$; Taiyo Yuden co., ltd.) capacitors are connected in parallel. 


\subsection{Active devices}

In the primary side of this flyback converter, it was the MOSFET device that was responsible for the switching function. The SiC-MOSFET (SCT3030AL, voltage: $650 \mathrm{~V}$, current: $70 \mathrm{~A}$, ROHM co., ltd.) is a power MOSFET made of $\mathrm{SiC}$ semiconductor with a trench-wall construction for reducing resistance in the parasitic JFET region [11]. It is expected that the $\mathrm{SiC}$ power semiconductor will perform under a high withstand voltage and large current as used in the switching device [12].

In the secondary side of this converter, it was the JFET device that was responsible for the rectifying function. The SiC-JFET (UJN1205K, voltage: $1200 \mathrm{~V}$, current: 38 A, United Silicon Carbide Inc.) was adopted as the rectifying device. The normally-on JFET receives the same signal for switching control on the primary side. It is presented in Fig. 2, the static characteristics of two types of active devices which were actually used.
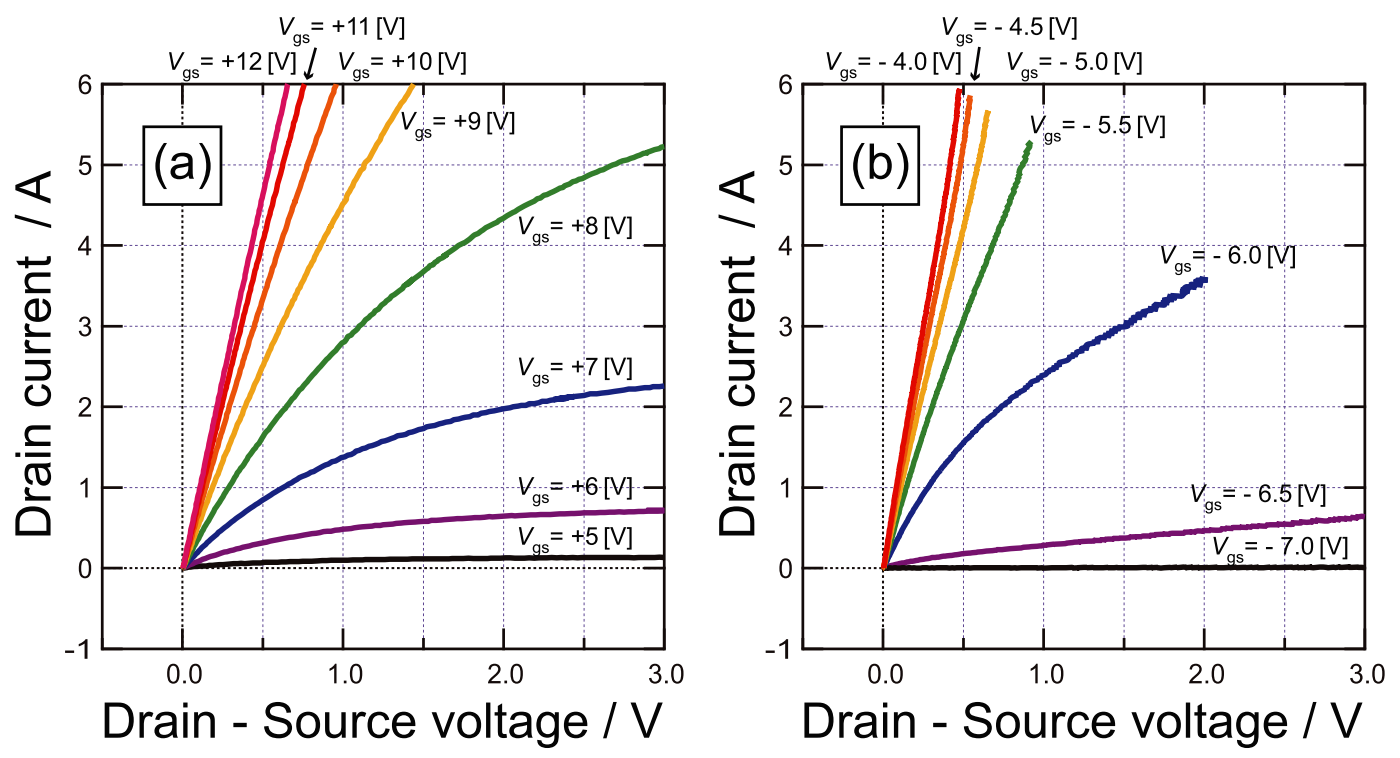

Fig. 2. Static characteristics of two types of active devices. (a) The SiCMOSFET used as the switching device, and (b) The SiC-JFET used as the rectifying device.

\subsection{Transformer}

The secondary coil of the transformer is used as a choking coil in the flyback converter. There is an air-gap within the pulse transformer-core to prevent a decrease in electric current due to magnetic saturation [1]. In the case of the magnetic core, such as the air-gap, the coupling coefficient was inevitably less than 100\%. Further, energy losses caused by leakage flux from the air-gap decrease the power conversion efficiency. As for the problem of latent heat during miniaturization, the area surrounding the air-gap can easily reach high temperatures. Therefore, it is necessary to consider problems associated with heat radiation.

We adopted a new magnetic material "Liqualloy," which was developed by Alps electric co., ltd. Since this magnetic material has good magnetic saturation characteristics, there is no need for an air gap. Thus, the losses associated with the air gap do not occur. We selected a toroidal core (29.5-mm outer diameter, 12.6-mm inner diameter, 14.0-mm height, 80.1-mm magnetic path length, 82.4- $\mathrm{mm}^{2}$ sectional area) without an air gap. We employed a polyester-enameled copper wire (PEW) with a 0.5-mm diameter for the primary and secondary windings. Each winding exhibits 40 turns, and both have a self-inductance of $150 \mu \mathrm{H}$ for an operating frequency of $1 \mathrm{MHz}$.

Figure 3 shows the magnetic-flux-density $(B)$ and magnetic-field-strength $(H)$ curve characteristic of the magnetic properties of two types of transformer core material and corresponding to operating frequencies. Figure 3(a) is the curve of the ferrite-core measured at $10 \mathrm{kHz}$ as the reference, and the hysteresis characteristic is confirmed. It showed magnetic saturation even at frequencies higher than $10 \mathrm{kHz}$, and the hysteresis loss also increased. We pointed out that the self-inductance of the 


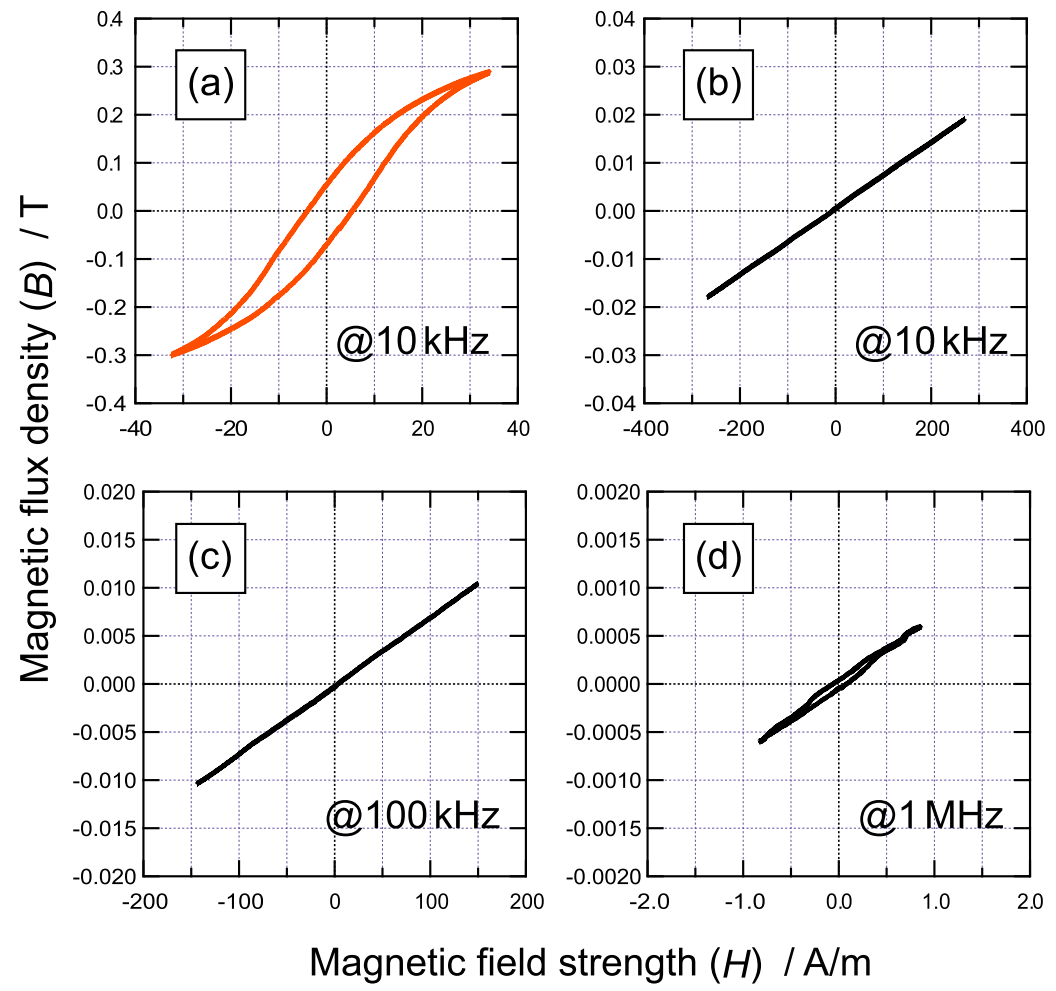

Fig. 3. The $B-H$ curve characteristic of the magnetic properties of two types of transformer core material and corresponding to operating frequencies. Ferrite core (reference material) at $10 \mathrm{kHz}$, (b) Liqualloy core at $10 \mathrm{kHz}$, (c) Liqualloy core at $100 \mathrm{kHz}$, and (d) Liqualloy core at $1 \mathrm{MHz}$.

transformer which adopted the ferrite-core was also designed at $150 \mu \mathrm{H}$. On the other hand, Figs. 3(b)(d) are curves when the liqualloy-core is adopted for the transformer. The liqualloy has linearity up to the frequency band of at least $1 \mathrm{MHz}$, and the saturation characteristic has not been measured.

\subsection{Isolated gate driver}

Isolated gate drivers must guarantee the prevention of fluctuation and conduction-noise without special setups. We experimentally compared the frequency characteristics of several types of isolated gate drivers with Si-8235 (Silicon Lab.), which was adopted as an isolated gate driver in the study. We developed a gate driver circuit for which the circuit pattern is specifically designed to minimize parasitic impedance. The switching trigger signal is transmitted to the isolated gate driver through the pulse generator (81110A; Agilent). On the primary side, to ensure a fast switching operation using SiC-MOSFET as the normally-off type, the gate-source voltage $\left(V_{\mathrm{gs}-\mathrm{M}}\right)$ were set at the pulse-shaped waveform with binary level at $0 \mathrm{~V}$ (off-state) and $12 \mathrm{~V}$ (on-state).

Conversely, on the secondary side, to achieve the fast rectifying operation by the SiC-JFET as the normally-on type, the gate-source voltage $\left(V_{\mathrm{gs}-\mathrm{J}}\right)$ were set at the pulse-shaped waveform with binary level at $0 \mathrm{~V}$ (on-state) and $-12 \mathrm{~V}$ (off-state). There is a feature that is control by the negative potential is achieved by making the gate potential equal to the ground potential, and then varying the source potential.

\subsection{Measurement for evaluation}

We simultaneously observed the flyback converter using an oscilloscope (DLM4038; Yokogawa Electric Corp.) and two current probes, (701918; Yokogawa Electric Corp.) while analyzing the transient behavior. The following state variables were measured: the gate signal $\left(v_{\mathrm{g}}\right)$, gate-source voltage $\left(v_{\mathrm{gs}-\mathrm{M}}\right)$, drain-source voltage $\left(v_{\mathrm{ds}}\right)$ of the SiC-MOSFET, gate-source voltage $\left(v_{\mathrm{gs}-\mathrm{J}}\right)$ of the SiCJFET, input voltage $\left(v_{\text {in }}\right)$, current of the primary side $\left(i_{1}\right)$, output voltage $\left(v_{\text {out }}\right)$, and current of the secondary side $\left(i_{2}\right)$. In addition, the calculated value $\left(p_{\mathrm{MOS}}\right)$ was obtained by multiplying the 
drain-source voltage $\left(v_{\mathrm{ds}}\right)$ with the current of the primary side $\left(i_{1}\right)$ associated with the loss incurred by the SiC-MOSFET.

The current probe delay was corrected to evaluate the high-speed switching operation. Without this correction, an error remains in the calculation of switching losses via the detection-delay of the current probe, because the observed waveforms have a short period owing to the fast-switching operation. It is necessary to correct the delay of the measured data caused by the current probe. The delay time between the voltage probe and the current probe measured $10 \mathrm{~ns}$, based on results of the preliminary experiment in which the response was confirmed between the voltage waveform and the current waveform. Then, considering all experimental results, there are the temporal waveforms corrected by the delay of the current probe.

\section{Results and discussions}

We designed the flyback converter with snubber circuit for operating frequencies of $100 \mathrm{kHz}$ and $1 \mathrm{MHz}$, respectively. The output supplies a direct voltage of $15 \mathrm{~V}$, and the duty ratio was fixed as $50.0 \%$.

Figure 4 shows the waveforms of the voltage and the current at the $100 \mathrm{kHz}$ switching operation. First, it was confirmed that the gate-source voltages of both the SiC-MOSFET $\left(v_{\mathrm{gs}-\mathrm{M}}\right)$ and the SiCJFET $\left(v_{\text {gs }-J}\right)$ were simultaneously applied according to the one-gate-signal design concept. Second, it was found that an accumulation of energy from the linearly rising current waveform on the primary side $\left(i_{1}\right)$, and energy emission from the linearly descending current waveform on the secondary side $\left(i_{2}\right)$, were correctly alternately performed. Finally, the electric power conversion efficiency had accomplished $91.9 \%$. The total value of switching losses and conduction losses of the SiC-MOSFET was calculated to be $89.0 \mathrm{~mW}$.

Figure 5 shows the waveforms of voltage and current at $1 \mathrm{MHz}$ switching operation. Similarly, it was confirmed that the gate-source voltage $\left(v_{\mathrm{gs}-\mathrm{M}}\right)$ of the SiC-MOSFET and the gate-source voltage $\left(v_{\mathrm{gs}-J}\right)$ of the SiC-JFET were simultaneously applied according to one-gate-signal in accordance with the design concept. Here, we compared the values of the input parasitic capacitances of the SiCMOSFET (approximately $1500 \mathrm{pF}$ ) and the SiC-JFET (approximately $1000 \mathrm{pF}$ ), respectively. The
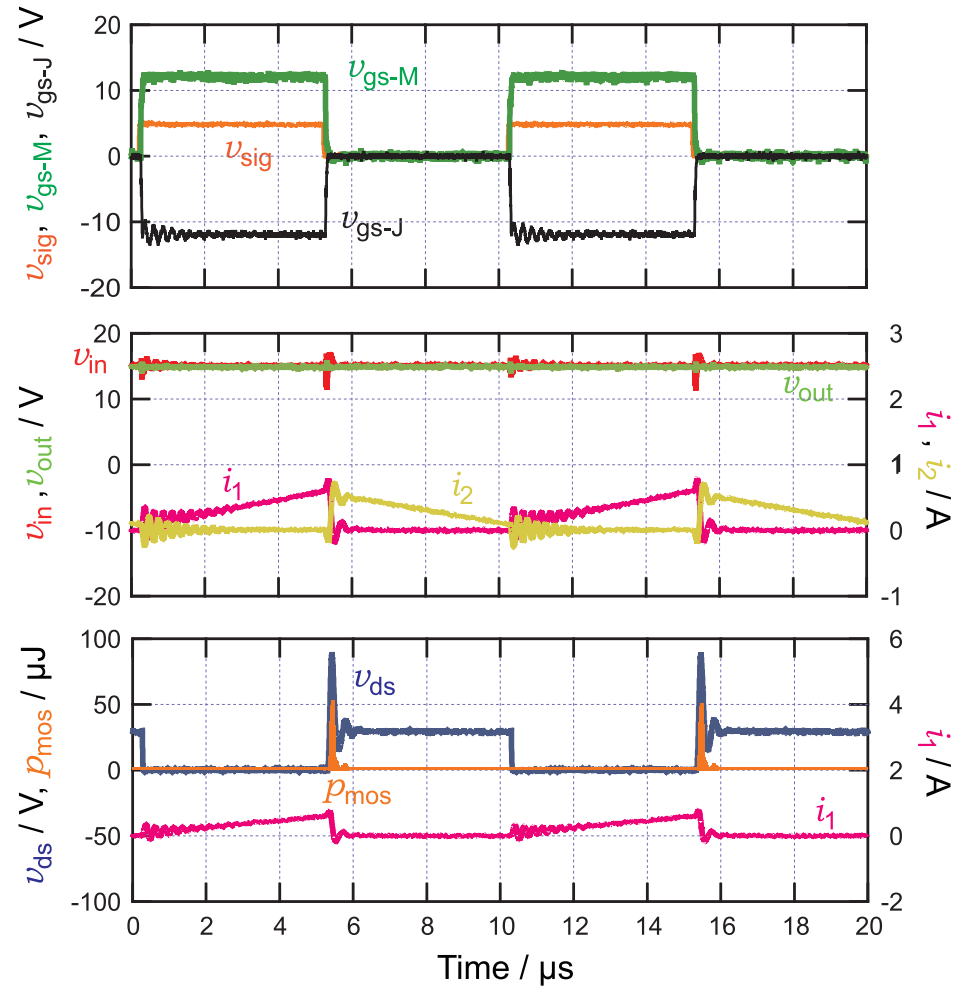

Fig. 4. Oscillograms of $V_{\mathrm{gs}}, V_{\mathrm{ds}}, V_{\mathrm{in}}, V_{\mathrm{out}}, I_{1}$, and $I_{2}$ at $f_{\mathrm{sw}}=100 \mathrm{kHz}$ in $15 \mathrm{~V}$ output voltage. 

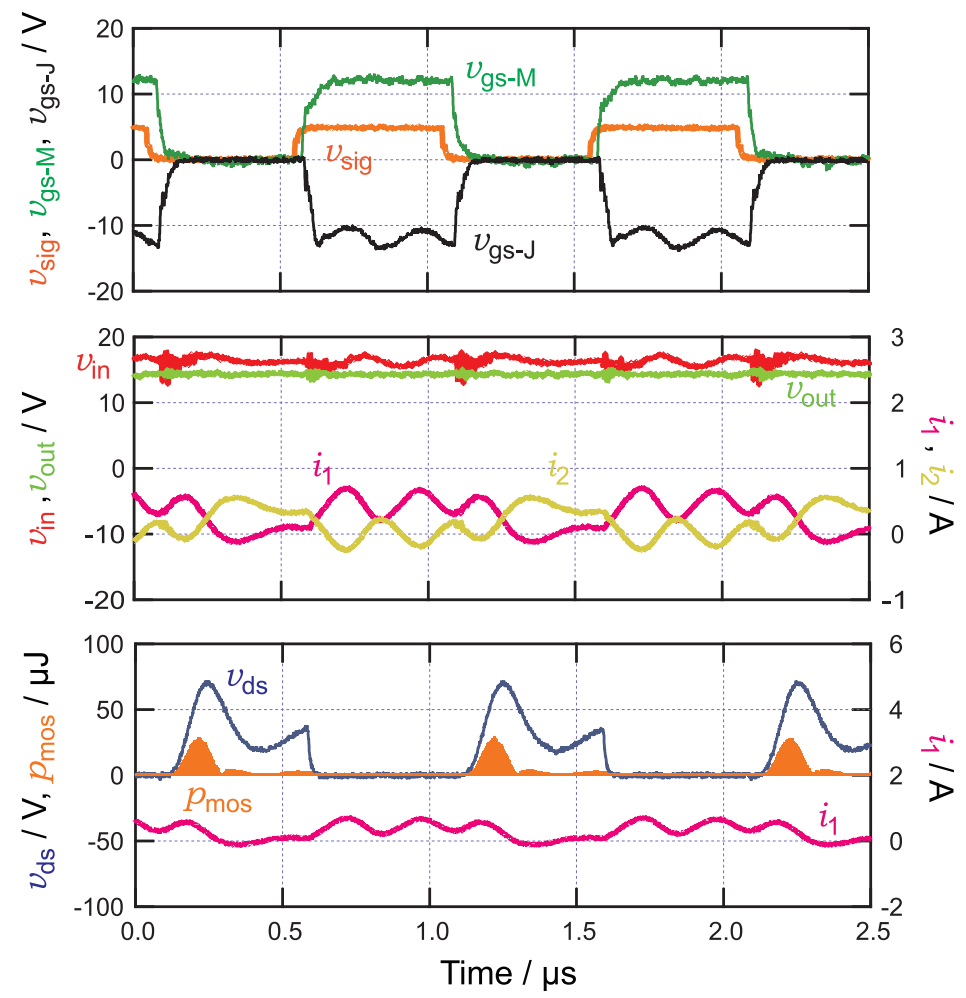

Fig. 5. Oscillograms of $V_{\mathrm{gs}}, V_{\mathrm{ds}}, V_{\mathrm{in}}, V_{\mathrm{out}}, I_{1}$, and $I_{2}$ at $f_{\mathrm{sw}}=1 \mathrm{MHz}$ in $15 \mathrm{~V}$ output voltage.

rising waveform of the SiC-JFET with a small input parasitic capacitance value was steep. The influence becomes apparent at the time when fast-driven at approximately $1 \mathrm{MHz}$ switching operation.

Second, although the output voltage at the set value of $15 \mathrm{~V}$ is stably output, the vibration phenomenon of the frequency component of approximately $3.2 \mathrm{MHz}$ is confirmed in both the current waveforms on the primary side $\left(i_{1}\right)$ and the secondary side $\left(i_{2}\right)$. The electric power conversion efficiency accomplished $61.6 \%$. The total value of switching losses and conduction losses of the SiC-MOSFET was calculated to be $134 \mathrm{~mW}$.

Here, we clarified how the surge voltage and the tail current are decided. There are two factors: the parasitic capacitance of the power MOSFET and the parasitic inductance of the circuit pattern in the flyback converter. The parasitic capacitance of the SiC-MOSFET and SiC-JFET are separated into input capacitance $\left(C_{\mathrm{rss}}\right)$, feedback capacitance $\left(C_{\mathrm{rss}}\right)$, and output capacitance $\left(C_{\mathrm{oss}}\right)$. Each value is known to have junction capacitances within the range of a few nanofarads [11]. We have designed this circuit such that the hard-wiring length of the circuit can be shortened as much as possible. The parasitic inductance of the circuit-pattern in the gate driver was measured within several hundred nanohenries. The resonant frequency of the flyback converter was calculated as several megahertz from these parasitic components [14].

It is also known that power loss at high-speed switching operation limits the use of magnetic components [15]. As a future task, the limits of switching-speed in our flyback converter circuit should consider not only the parasitic capacitances of the active devices, but also the magnetic saturation of the magnetic core material of the transformer.

As future tasks, since the increase in losses in high-frequency operation induces thermal destruction of the devices, it needs to establish thermal design considering the placement of circuit elements. Furthermore, we aim to achieve $50 \mathrm{~W}$ class output corresponding to 10 times of this study.

\section{Conclusions}

We fabricated a flyback converter with an output voltage of $15 \mathrm{~V}$ under the $f_{\mathrm{sw}}=1 \mathrm{MHz}$ operation. The circuit was operated while ensuring the electrical insulation by the transformer without air-gap and the isolated-gate-driver. We confirmed experimentally the reliable complementary operation of 
the circuit using the SiC-MOSFET as the switching device and the SiC-JFET as the rectifying device. The efficiency of this power conversion was calculated to be $61.6 \%$ at $1 \mathrm{MHz}$ operation by waveform observation.

\section{Acknowledgments}

This research was partially supported by the Cross-Ministerial Strategic Innovation Promotion Program for Next-Generation Power Electronics.

\section{References}

[1] D. Murthy and M.K. Kazimierczuk, Proc. Electrical Insulation Conference and Electrical Manufacturing Expo., p. 408, 2005.

[2] H. Ohashi, I. Omura, S. Matsumoto, Y. Sato, H. Tadano, and I. Ishii, IEICE Trans. Commun., vol. E87-B, p. 3422, 2004.

[3] L.F. Casey and M.F. Schlecht, IEEE Trans. Power Electron., vol. 3, p. 72, 1988.

[4] B.J. Baliga, IEEE Electron Device Lett., vol. 10, p. 455, 1989.

[5] T. Meade, D. O'Sullivan, R. Foley, C. Achimescu, M. Egan, and P. McCloskey, Twenty-Third Annual IEEE Applied Power Electronics Conference and Exposition, p. 3, 2008.

[6] K. Harada and T. Ninomiya, IEEE Trans. Aero. Elec. Sys., vol. AES-15, p. 209, 1979.

[7] H.J. Sira-Ramirez and R. Silva-Ortigoza, Control Design Techniques in Power Electronics Devices (Springer-Verlag: London, 2006).

[8] Z.J. Shen, D.N. Okada, F. Lin, S. Anderson, and X. Cheng, IEEE Trans. Power Electron., vol. 21, p. 11, 2006.

[9] Y. Li, J.A. Jr. Cooper, and M.A. Capano, IEEE Trans. Electron Devices, vol. 49, p. 972, 2002.

[10] K. Tone, J.H. Zhao, L. Fursin, P. Alexandrov, and M. Weiner, IEEE Electron Device Lett., vol. 24, p. 463, 2003.

[11] T. Nakamura, Y. Nakano, M. Sasagawa, T. Otsuka, M. Aketa, and M. Miura, Intl. Symp. Automation and Test, p. 1, 2011.

[12] J.A. Jr. Cooper, M.R. Melloch, R. Singh, A. Agarwal, and J.W. Palmour, IEEE Trans. Electron Devices, vol. 49, p. 658, 2002.

[13] T. Nakamura, M. Miura, N. Kawamoto, Y. Nakano, T. Otsuka, T. Okumura, and A. Kamisawa, Physica Status Solidi (A), vol. 206, p. 2403, 2009.

[14] N. Satoh, H. Otake, T. Nakamura, and T. Hikihara, IECON 2015 - 41st Annual Conference of the IEEE Industrial Electronics Society, p. 001376, 2015.

[15] A.W. Lotfi and M.A. Wilkowski, Proc. IEEE, vol. 89, p. 833, 2001. 